\title{
On a possible endogenous traumatization of brain, spinal cord, and nerve roots
}

The first paper (1982) on the venous origin of multiple sclerosis

\author{
F Schelling 1 \\ ${ }^{1}$ Private practice. A-6850 Dornbirn (Austria), Arlbergstrasse 3
}

submitted: Jul 25, 2017, accepted: Jul 27, 2017, EPub Ahead of Print: Aug 1, 2017

Conflict of interest: None

DOI: 10.24019/jtavr.29 - Corresponding author: Dr. Franz Schelling, dr.franz.schelling@gmail.com

(C) 2017 Fondazione Vasculab impresa sociale ONLUS. All rights reserved.

Abstract Translation and reprint of the paper "Möglichkeiten der endogenen traumatisation von gehirn, rückenmark und nervenwurzeln", by Franz Schelling, selfpublication Dornbirn (Austria) 1982.

Keywords Multiple sclerosis, Venous hypothesis, Cerebral reflux

\section{(i) On the problem of venous reflux towards human brain and spinal cord}

\section{(A) Basic considerations}

The occasional absence of the vein valves located at the inferior bulb of the internal jugular was already described 135 years ago (Gruber 1847).

In these veins, the valves alone withstand a reflux from the cava veins into the main venous drainages of the brain.

Intrathoracic pressure attains values which would drive up a blood column of a two and a half meters height e.g. during heavy coughing (Rollet 1877, Comroe, Gerlach, Bodenstab 1968), meeting slightly negative values in the superior sagittal sinus of persons standing erect (Ganong, Auerswald 1974).

This raises the question: What happens, once such central venous excess pressures are pushing back into particular venous draining systems of the central nervous system?

Venous pressure waves proceed at a speed of 1 to $2.5 \mathrm{~m}$ per second, this in dependence of the vascular filling pressure (Knebel, Wick 1958). In the presence of venous reflux, intrathoracic excess pressures can thus involve cerebral veins in less than the tenth of a second. The concurrent damming up of venous blood in the other vascular drainages of the central nervous system raises cerebrospinal fluid pressures several tenth of seconds up to seconds later (Gilland 1962, Lakke 1975). In the intervening time the cerebral veins exposed to venous reflux are in part burdened by enormous peaks in their transmural pressure (Fig. 1). They will expand up to the point at which no cerebrospinal fluid is to be any longer displaced out of their neighborhood respectively until the pressure gradient to encompassing cerebrospinal fluid and vascular compartments has been leveled out. The mechanical resistance of the brain tissues (Aoyagi, Hayakawa, Masuzawa 1981) and even of the reinforced cones of the vascular entries into the pia mater (Schaltenbrand 1955) are not resistant to the forces which are to be exerted thereby.

From studies into the vascular architecture of the human brain (Pfeifer 1930) mainly a straightening of venous bows has to be anticipated. From Laplace's law the widening of larger venules has to be expected first: In the central nervous system they show, in relation to their diameter, particularly weak walls. The combination of these activities can't remain without consequences for the 
surrounding structures, especially regarding the vulnerable units formed by oligodendroglia cells and myelin sheaths. This is evident from the riddling of the white matter about arteries which lost their normal pulsation-dampening form
(Pfeifer 1930, Yates 1976). This irrespective of the virtually synchronous and even transmission of the arterial pulse on well pressure-adapted vascular tubes.
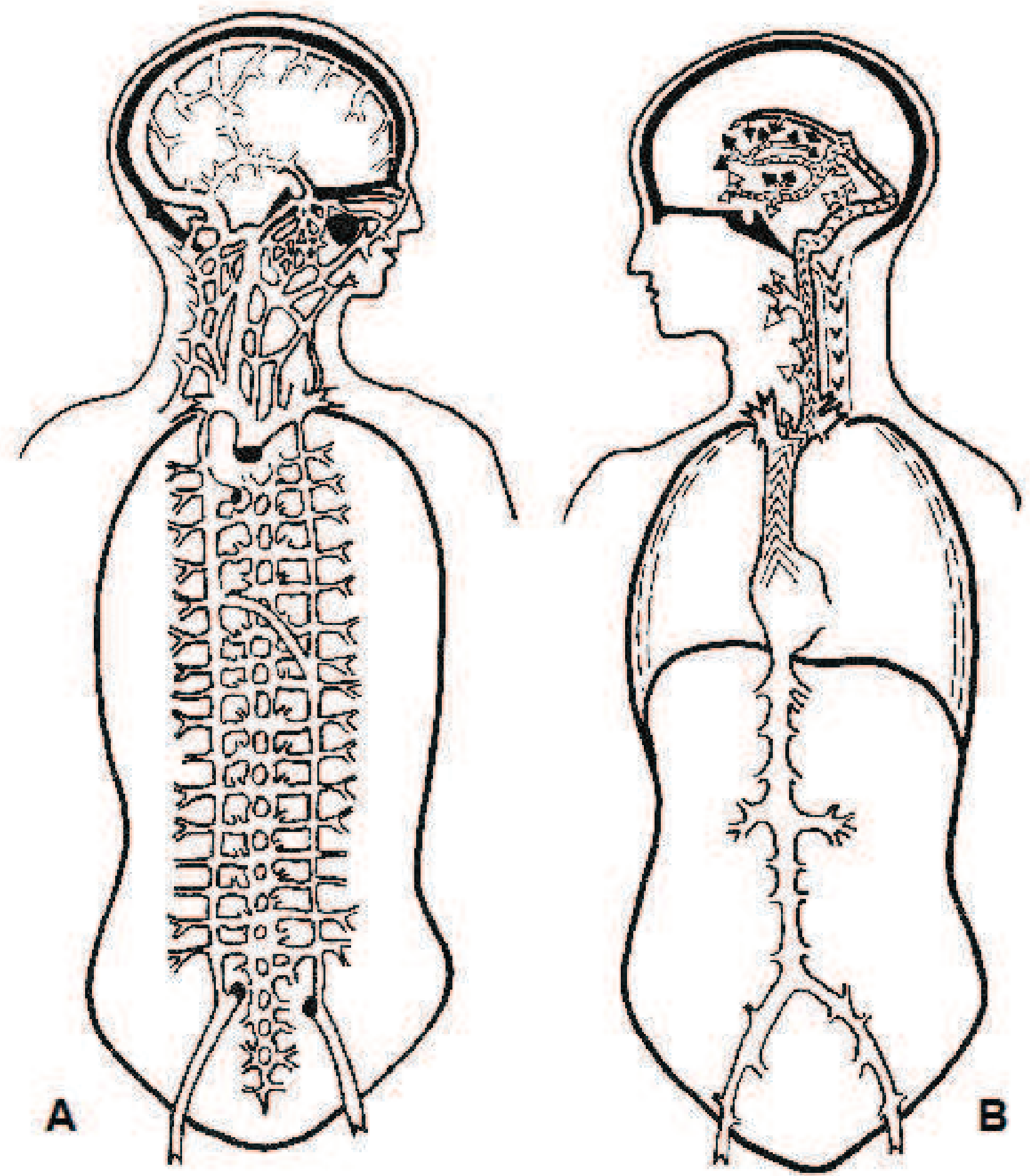

Fig. 1: Compare the pressure distribution in venous stasis (A) with the pressure distribution in a reflux via one internal jugular vein $(B)$

Over and above this a mechanical overstraining fluctuations of cerebrospinal fluid causing higher pressure of nervous structures is also possible by the resulting gradients between cerebral ventricles and intracranial 
cisterns respectively such within the spinal subarachnoid space on the one hand, and such within spinal subarachnoid space and the sheath of the optic nerve on the other. The extremes of these pressure gradients have certainly a higher pathogenic relevance than the continuous work of the secretion of cerebrospinal fluid. And it is at narrow passages respectively on the optic disc that they will make themselves much more severely felt.

Reductions in the brain and spinal cord's leeway to movements will finally be as detrimental with movements due to fluctuations of blood and cerebrospinal fluid as they are with intraspinal displacements due to bodily movements (O'Connell 1946, Breig 1964).

\section{(B) Special zones of attack of venous reflux and of fluctuations of cerebrospinal fluid}

The mitigation of venous refluxes into one of the main pathways of the brain's venous drainage (the same applies to the effects of local pressure increases due to venous stasis) is the stronger, the better refluxes can be dissipated into extracranial vascular domains. The other way round: The venous refluxes' bearings on the nervous tissues will be the more intense, the more narrowly circumscribed the involved cerebral and spinal drainage systems are, and the faster they are reached. In respect of the main variations in the brain and spinal cord's venous drainage, the following directions of venous refluxes are to be indicated:

(a) Refluxes into immediate tributary vessels of internal jugular veins, of the sigmoid sinus, the marginal sinus, the transverse sinus, respectively the inferior petrosal sinus on the right respectively left.

(b) Refluxes into tributary vessels of the occipital sinus, straight sinus and inferior sagittal sinus, and/or the superior sagittal sinus. With complete septations of the confluence of sinuses and the straight sinus, the possibility of refluxes from one of the transverse sinuses into one of the internal cerebral veins appears particularly disquieting.

(c) Refluxes into tributary vessels of the smaller dural sinuses of the middle cranial fossa and of the cavernous sinus. Owing to their high flow resistance against venous refluxes, and especially with stronger connections to the pterygoid plexus, no substantial expansions of the tributary vessels, entering mainly via the Sylvian fissure, are to be expected.

(d) Venous backlashes into the epidural venous plexuses of the spinal canal. Commonly dissipated in a closely-meshed, often voluminous, widely spread plexus of veins, they might rarely result in circumscribed expansions of epidural convolutes of veins, and especially in direct refluxes into spinal radicular veins.

The central nervous system's grey portions (e.g. cortex and nuclei) are relatively well prepared to contain the changing venous pressures. This on account of their dense feltwork of neuronal, glial and, in part, also connective fibers, as well as the dense vascular networks of pia, cortex and nuclei.

What appears utmost at risk are, on the other hand, the delicate, soft structures of the white matter in particular in the neighborhood of large volumes of cerebrospinal fluid, being approached, as this is prominently the case, along the outer angle of the lateral ventricles and this at varying angles by variously curved medullary veins (Figs. 2 and 3).

Heavier fluctuations of cerebrospinal fluid result mainly from the divergence of the fluctuations of venous pressures and volumes in different drainage systems of cranial cavity and spinal canal. The critical factors, in this context, are the changing thoracic and abdominal respiratory pressures and the diversified inspiratory (vein collapses!) and expiratory conditions for the drainage of the different vascular compartments. Exaggerations of these fluctuations, namely on account of venous refluxes, potentially attack the intradural nervous structures by additional mechanisms (Fig. 4):

In displacing ventricular fluid, the expansions of the inner veins of the brain are capable of bulging weaker ventricular wall parts in direction of the cisterns. Pressing, for example, the floor of the third ventricle against the optic chiasm's posterior circumference.

With a low buffer capacity of the spinal dural sac respectively impediments to the displacement of cerebrospinal fluid in this direction, the optic disc can be damaged also by short-lasting, stronger ascents of the intracranial pressure over the intraocular pressure.

Intense cerebrospinal fluid shifts burden the adjacent surfaces with a propulsive force which attacks the anchorage points of the spinal cord and the nerve roots in an indirect way, this especially at narrow passages of the spinal canal.

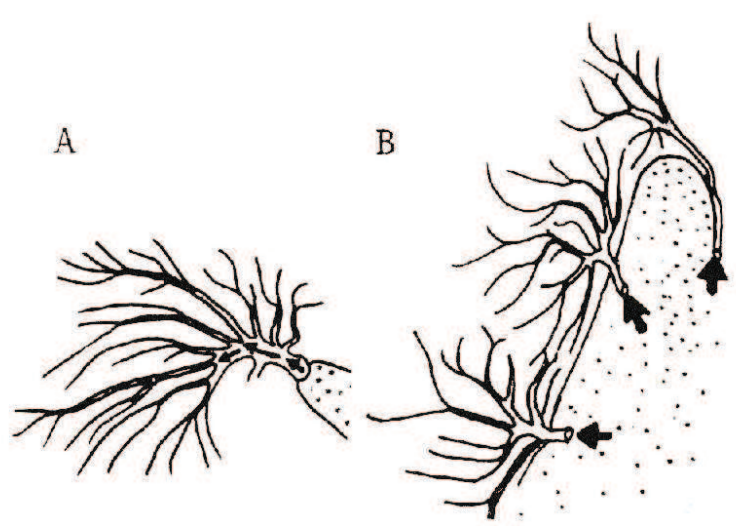

Fig. 2: The course of the medullary veins at the outer angle of the lateral ventricles (A sagittal, $B$ axial view). 
(In particular with higher CSF pressures) widenings and deformations of the spinal dural sac also strain the spinal cord via the insertions of its mooring ligaments, especially if the latter are already densely taught.

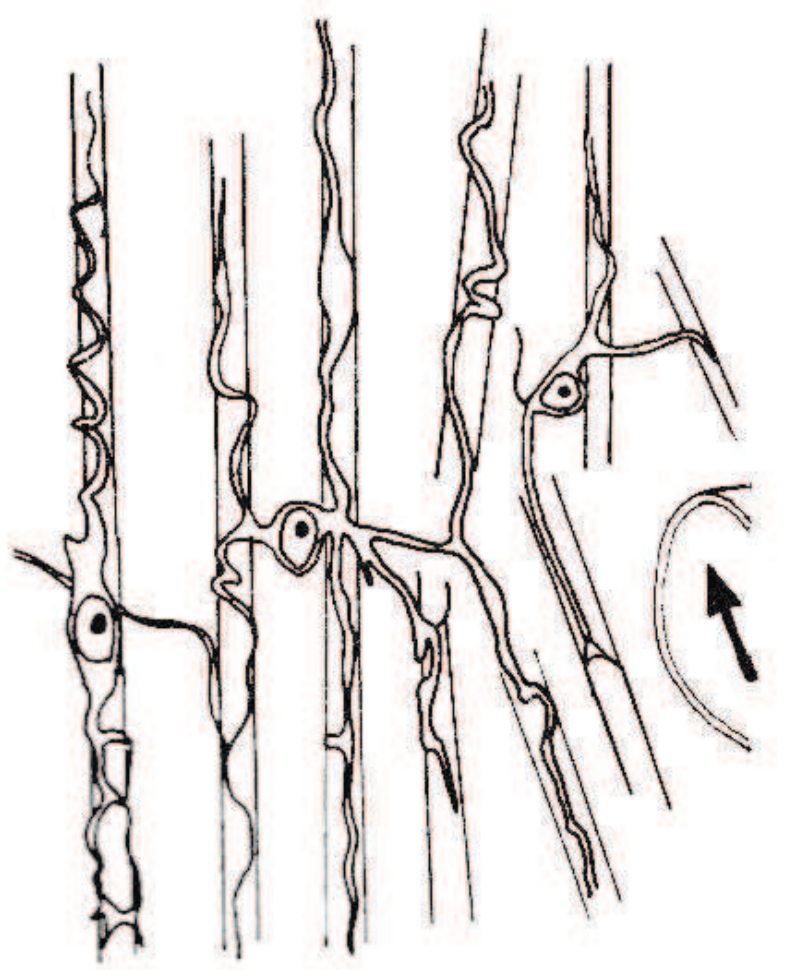

Fig. 3: Schematic drawing of the connection of oligodendrocytes and myelin sheaths.

Stronger displacements of the brain via tentorial notch and foramen magnum require a more massive increase of the intracerebral blood volume as a whole, involving also the capillary vessels - and this in dependence of a corresponding compliance of the spinal dural sac. With a narrowed spinal canal respectively with meningeal scars the spinal cord can be superficially damaged while floating more intensely.

The venous refluxes respectively and the fluctuations of cerebrospinal fluid will be the more intense, the lower the intradural pressure they meet and the slower a pressure rise they effect.

An involvement of the indicated pathomechanisms in the pathology and clinical presentation of central nervous respectively radicular affections may be mainly suspected where cerebral veins and myelin structures are affected first, and where pressures and temperatures inside and outside the human organism impact on a disease's course in an extraordinarily strong intradural pressure.

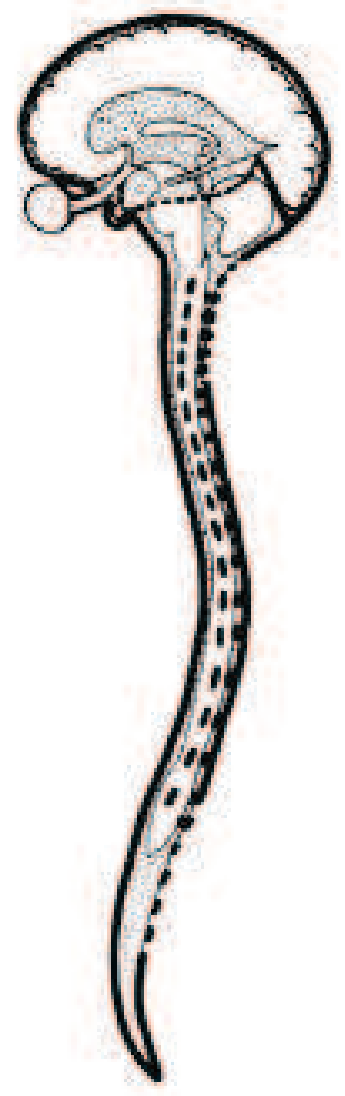

Fig. 4: The structures which stabilise and the intradural spaces offering leeway to the movements of brain and spinal cord.

(ii) Indications of [a missed kind of venous] endogenous traumatization of central nervous and radicular structures, as exemplified by multiple sclerosis

\section{(A) Clues of pathological anatomy and histology}

On character and nature of the given demyelinations:

Long and thin, in part branching bridges of cytoplasm connect the oligodendroglia cell to its up to fifty segments of myelin (Blackwood 1976, Ritter 1980): Fig. 3. Stronger distending and shearing forces which act on the nervous parenchyma are liable to destroy this trophic unit. This explains its mechanical vulnerability in traumatic injuries (Koenig, Dohrmann 1977), its selective damaging by more intense motions of cerebrospinal fluid (Bunge, Bunge, Ris 1960), and the prominence of myelin destructions in 
decompression disease (Haymaker 1957). Including the specifically located patterns of demyelination observed in multiple sclerosis (Peters 1958). It also explains the initial destruction of not the superficial but the intermediate layer of myelin sheath in the latter disease (Poser, Ritter 1980).

\section{Understanding the topography of lesions in multiple sclerosis:}

Character and location of the sclerotic plaques reflect the picture of the damage which the vascular expansions of venous refluxes is expected to produce down to the smallest detail.

This circumstance applies first to the extension and severity of the finger-shaped demyelination invading the semioval center via larger venules (Dow, Berglund 1942, Fog 1950).

Lhermitte (1950) and Lumsden (1975) stressed as well: The sclerotic foci are not centered on capillary vessels, as seen in central nervous infection or in a visceral [Systemic] Lupus Erythematosus, but around larger venules. The straightening of venous bends possibly accounts for the spot-shaped focis' scattering.

The striking proclivity to thromboses affecting veins downstream of recent plaques (Rossolimo 1904, Putnam 1937, Dow, Berglund 1942, Prineas 1975) possibly relates to vein wall damages due to reflux. Leaky brain veins (Broman 1964) may also form the point of exit for the observed derangements in the system of coagulation (Prineas 1975, Brunetti et al. 1981, Prosiegel et al. 1982).

What argues for a production of the spinal foci of multiple sclerosis by displacements of the spinal cord in relation to its sheaths is the lesions' lack of a vessel relationship (Falkiewicz 1926), and, above all, the cervical cord lesions' arrangement according to the insertions of the denticulate ligaments (Oppenheimer 1978).

The indicated pathomechanism also offers a plausible explanation for the spinal demyelinations' accumulation in the reach of spondylotic narrowings of the vertebral channel (Brain, Wilkinson 1957).

It also has to be pointed out that also the nerve roots, but not the rest of the peripheral nerve lengths are affected by primary demyelinations (Zimmermann, Netzky 1950). Both, however, have the same antigenic structure of their own.

After all that has been said, it has to be expected that the fibrohyaline changes of primarily venules, later possibly also capillaries, described by LUMSDEN in 1975, might commonly involve only the brain.

\section{(B) Epidemiological and clinical findings}

The indefinite and protean clinical picture of multiple sclerosis complicates epidemiological studies enormously. It was nonetheless possible to trace diverse conditions that further the development of the disease.

A familiar clustering of the disease in conjunction with a raised disposition to a variety of different nervous and mental diseases is no longer to be denied (Curtius 1959, Myrianthopoulos 1975, Poser, Ritter 1980).

What is equally evident: Neither the duration nor the intensity of a contact with MS patients change the probability of acquiring the disease (Myrianthopoulos 1975, Poser, Ritter 1975).

Globally it is the more probable for people to acquire the disease, the farther from the equator they have grown up (Kurland 1975).

The varying statements on the male/female ratio of the patients with multiple sclerosis point overall to a somewhat more frequent affection of women.

The distribution curves on the patients' age at the manifestation of the disease show a high peak in the bodily most active years of live.

What diverges extraordinarily are the opinions on the causal relevance of the diverse circumstances that coincide more frequently with the beginning respectively with later exacerbations of the disease process (childbirth, traumata, exertions, mental turmoil, overheating etc.) (Behrend 1957).

Dramatic symptom changes induced over and over again to asserting they were of a psychogenic, neurotic or hysteric nature.

What prevented the precise registration of these latter peculiarities seems to have been, on the one hand, the inability of reducing the diverse circumstances which release the disease to a common denominator. It might have also been blocked by the impossibility to bridge the gap to the established pathogenetic conceptions concerning the essence of multiple sclerosis.

In view of the preceding indications, patients with multiple sclerosis might be conceived to have a genetically reduced mechanical resistance and tension of their vascular walls, which predisposes to the development of venous refluxes into the venous drainages of the central nervous system.

A compensatory widening of the brain's vascular pathways for increasing its perfusion in colder surroundings so as to maintain the brain's temperature, or to ensure the brain's sufficient supply with oxygen (e.g. with iron deficiencies related to menarche) might contribute to the understanding of the relation between the prevalence of multiple sclerosis and geographic latitude on the one hand, 
and sexual factors on the other: The widening of veins is a factor which predisposes to valvular deficiencies and so to venous reflux.

Especially the typical relationships to the patients' age and the fact that exertions release bouts could be related to the occurrence of steeper and more massive ascents of the pressure gradient between central and intracranial veins.

What came to be explained, over and above this, is why weeks are passing before the first clinical manifestation of multiple sclerosis leaves its traces in the cerebrospinal fluid, but no inflammatory reactions (leucocytes, proteins, blood sedimentation rate) in the blood.

From this derives the necessity to examine the reflux conditions in the central nervous drainage systems in autopsies of persons who suffered from nervous and mental diseases, and in particular of multiple sclerosis. In this context also the circumstances underlying the aggravations and manifestations of multiple sclerosis ought to be clarified. As for the postulated pathomechanisms, the following questions attain clinical relevance in the attempt to discriminate the damages in which hemo- and cerebrospinal fluid dynamics may play a role:

How often, and with what a delay, is the beginning of the disease preceded by events in which the valves at the inferior bulb of the internal jugular veins can be damaged? After accidents and other mechanical impacts a delay of maximally days, with inflammatory processes affecting the venous periphery a delay of weeks, months, and even years seems imaginable.

How frequently and with what a delay (of maximally days) result conditions causing excessive rises in central venous pressures (coughing, childbirth, exertions and others) in relapses or a progression of the disease? Whenever possible, the degree of straining ought to be quantified.

How far are other factors favouring refluxes respectively raising their efficacy of relevance (e.g. heat, falling ambient pressures, bending over, lying down)?

How often do patients experience feelings of head/ top pressure respectively a tinnitus in being involved in circumstances which further refluxes?

How often are there affections of a thyroid gland relating to the pathways of a given reflux?

How often are there signs of a meningeal, radicular or pial irritation? (pains on nerve stretching? meningism? Lhermitte sign? how often is knocking at interlaminar spaces, spinous processes, cranium causing pains?)

How often are the warpings or more serious and complex distortions of the spine? How relate abnormal cerebrospinal fluid findings (cell counts, immunoglobulins, relation of albumin to globulins) to what has been given above?

Which neurological and mental problems affect the multiple sclerosis patients' kinship preferentially?

\section{Clinical outlook}

The addressed problems appear to have practical implications: Once the pathogenic significance of venous refluxes in direction of brain and spinal cord has been determined and is to be individually assessed, a few minimally invasive examinations (including radiographs and sonograms) would lead up to the concerned patients' plain and causal treatment which consists in the prevention of the refluxes' recurrence.

\section{References}

Aoyagi N, Hayakawa I, Masuzawa H. Compliance of brain. In Dietz H, Metzel E, Langmaid C (eds). Abstr 7th Int Congr Neurol Surg. Stuttgart, Thieme 1981, p. 215

Behrend RC. Krankheitsfoerdernde Faktoren in der Pathogenese akut entzuendlicher Erkrankungen des ZNS. Fortschr Neurol Psychiat $1957 ; 25: 365-439$

Brain R, Wilkinson M. The association of cervical spondylosis and disseminated sclerosis. Brain;1957:80:456-78

Breig A. Dehnungsverschiebungen von Dura und Rueckenmark im Spinalkanal. Fortschr Neurol Psychiat 1964;32:195-208

Broman T. Blood-brain barrier damage in multiple sclerosis; supravital test observations. Acta Neurol Scandinav. 1964(Suppl 40);10:21-4

Brunetti A et al. Rheological and fibrinolytic findings in multiple sclerosis. J Neurol Neurosurg Psychiat 1981;44:340-3

Bunge RP, Bunge MB, Ris H. Electron microscopic study of demyelination in an experimentally induced lesion in adult cat spinal cord. J Biophys Biochem Cytol 1960;7:685-96

Comroe JH, Gerlach HA, Bodenstab H. Physiologie der Atmung. Stuttgart, Schattauer 1968

Curtius F. Neuere Ergebnisse der erbbiologischen Multiple Sklerose-Forschung. Fortschr Neurol Psychat 1959;27:161-84

Dow RS, Berglund G. Vascular pattern of lesions in multiple sclerosis. Arch Neurol Psychiat 1942;47:1-18

Falkiewicz T. Zur Pathogenese der Multiplen Sklerose. Arb neurol Inst Wien 1926;28:172-96 
Fog T. Topographic distribution of plaques in the spinal cord in multiple sclerosis. Arch Neurol Psychiat (Chic.) 1950;63:382-414

Ganong FW, Auerswald W. Lehrbuch der medizinischen Physiologie. 3. Aufl. Berlin, Springer 1974

Gilland O. Cerebrospinal fluid dynamics in spinal subarachnoid block I. Acta Neurol Scandinav 1962;38:285-306

Gruber W. Vier Abhandlungen aus dem Gebiete der medicinisch-chirurgischen Anatomie. Foerstner, Berlin 1847

Haymaker W. Decompression sickness. In Lubarsch O, Henke F, Roessle R (eds) Hdb spez path Anat Hist vol XIII/1B, Berlin, Springer 1957, pp.1600-72

Knebel R, Wick E. Ueber den Einfluss der Atmung auf den zentralen Venendruck. Z Kreislaufforschg 1958;47:623-37

Koenig G, Dohrmann GJ. Histopathological variability in standardized spinal cord trauma. J Neurol Neurosurg Psychiat 1977;40:1203-10

Kurland LT. The epidemiologic characteristics of multiple sclerosis. In Vinken PJ, Bruyn GW (eds). Handbook Clin Neurol. Amsterdam, North Holland 1975, vol 9, pp. 63-84

Lakke JPWF. Detection of obstruction of the spinal canal by CSF manomentry. In Vinken PJ, Bruyn GW (eds). Handbook Clin Neurol. Amsterdam, North Holland 1975, vol 19/1, pp. 91-123

Lumsden CE. The neuropathology of multiple sclerosis. In Vinken PJ, Bruyn GW (eds). Handbook Clin Neurol. Amsterdam, North Holland 1975, vol 9, pp. 217-319

Lhermitte F. Les leuco-encephalites. Paris, Flammarion 1950

Myrianthopoulos NC. Genetic aspects of multiple sclerosis. In Vinken PJ, Bruyn GW (eds). Handbook Clin Neurol. Amsterdam, North Holland 1975, vol 9, pp. 85-106

O'Connell J. The clinical signs of meningeal irritation. Brain 1946;69:9-21

\section{Notes to the reprint Notes of the Editor}

This paper ${ }^{1}$ was just the first one of a small series of articles and poster presentations by F Schelling which appeared in the ' $80 \mathrm{~s}^{2,3}$, dealing with the hypothesis of the venous origin of multiple sclerosis (MS). We thank the Author for having agreed to make the huge job of translating it from German, thus giving our readers the opportunity of appreciating a forgotten work about the venous cerebral circulation.

\section{Notes of the Author}

This first attempt to deblur the thinking on venous refluxes into brain and spine had, and still has its shortcomings. First of all, because no data are available about the speed of ascent and eventual height of the pressure peaks which occur in the internal jugular veins. Besides this, because the effects of muscular and external impacts exterted on the internal jugular veins upstream of sporadic and functional occlusions have as yet not been duly taken into account.

The occurrence of a one-sided incompetence of the valve securing the upper end of the inferior bulb of right respectively left
Oppenheimer DR. The cervical cord in multiple sclerosis. Neuropath Appl Neurobiol 1978;4:151-62

Peters G. Multiple Sklerose. In Lubarsch O, Henke F, Roessle R (eds). Hdb spez path Anat Histol. Berlin, Springer 1958, vol XII/2A, pp. 525-602

Pfeifer RA. Grundlegende Untersuchungen fuer die Angioarchitektonik des menschlichen Gehirns. Berlin, Springer 1930

Poser S, Ritter G. Multiple Sklerose in Forschung, Klinik und Praxis. Stuttgart, Schattauer 1980

Prineas JW. The etiology and pathogenesis of multiple sclerosis. In Vinken PJ, Bruyn GW (eds). Handb Clin Neurol. Amsterdam, North Holland 1975, vol. 9, pp. 107-160

Prosiegel M, Neu I, Pfaffenrath V, Nahme M. Thrombocytenaggregation und Multiple Sklerose. Nervenarzt 1982;53:227-30

Putnam TJ. Evidences of vascular occlusion in multiple sclerosis and encephalomyelitis. Arch Neurol Psychiat (Chic.) 1937;37:1298-1321

Rollett E. Dtsch Arch klin Med 1877;19:295, zit. n. Vierordt H. 1906

Rossolimo J. Rueckenmark. In Flatau E, Jacobson L, Minor L (eds). Hdb path Anat Nervensystem. Berlin, Karger 1904, p. 690

Schaltenbrand G. Plexus und Meningen. In Moellendorf Wv, Bargmann W (eds). Hdb mikr Anat Menschen. Berlin, Springer 1955, vol. IV/2, pp. 55,156

Vierordt H. Anatomische, physiologische und physikalische Daten und Tabellen. Jena, Fischer 1906, p. 263

Yates PO. Vascular diseases of the central nervous system. In Blackwood W, Corsellis JAN (eds). London, Arnold 1976, pp. 86-147

Zimmerman HM, Netsky MG. The pathology of multiple sclerosis. Ass Res Nerv Dis Proc 1950;28:271-312

internal jugular vein won't be questioned by anyone. Nor it's being the only valve which guards the brain against excess pressures that emerge from below.

What seems not to be known as well are the ways in which refluxes spread pushing up via, or from, internal jugular veins. No better the fact that an absence of the confluence of sinuses, of each cranial venous outlet bypassing a principal one has repeatedly been observed.

Impressive anatomical findings of varicose dilations of posterior condylar emissary veins relating to such of the upper jugular bulb made in $1973 \mathrm{had}$ pointed to the occurrence of voluminous refluxes passing from internal jugular into deep cervical veins. Less could be said about the excess pressures which the involved internal jugular veins' cerebral affluents are in such contexts burdened with.

In this context, observations of small veins connecting the upper end of the internal jugular directly with bulbar veins, and such of the exceptional feeding of an (rather the left) internal jugular vein via an isolated lateral and straight sinus primarily by the internal cerebral veins (or but one of them) are calling for special attention. They point to the fact that refluxes from an internal jugular vein will tend to have 
their most disastrous effects in precociously or selectively burdening a narrowly circumscribed venous domain.

Curiously enough, both brain damages and lesion dynamics which appear to perfectly reflect the postulated events have been described under the heading of multiple sclerosis.

Since this paper was published, no piece of evidence came forth, no objection was raised, which might have invalidated its content.

To the contrary, more and more data accrued which confirmed its critical indications in the one or the other respect. This at a rate rendering it more and more demanding to keep track of them (e.g. central/lesional vein/vessel sign).

Long forced to retire, I can but wonder who might achieve the feat of pulling all these strands of evidence together and so become entitled to fulfill my dream: The carefully planned and executed prevention of injurious venous refluxes into brain and spine.

\section{Acknowledgements}

The willingness of doctor Fausto Passariello to present my original argumentation for widening the scope of MS research accordingly can hardly be appreciated highly enough.

It is thanks to Mrs. Alison Fisher (Scotland), Dr. Elcio Machado (Brasil), and Prof. Jaap Valk (Netherlands) that my early work has not fallen into oblivion. I owe the links to the references 2) and 3) below to them.

If I did make any headway at all, it is yet because Prof. Werner Platzer tutored me in anatomy, Prof. Gerhard Breitfellner gave his permission to perform retrograde venous injection studies in MS and control autopsies, Prof. Walter Rhomberg paved the way to my poster presentations - all of this in nearby Austria.

The motivation to carry on, however, came from my most seriously affected MS patients.

Gaining decisive support from a congenial Prof. Colin Adams (England) who best showed how MS destroys, actually bursts its lesion veins in the brain ${ }^{4}$, and from admired Prof. Emil Beck (Austria) and kind Prof. Wilhelm Doerr (Germany) who acquainted me with parallel observations made after accidents 5 .

A deeply grateful,

Franz Schelling, M.D.

A-6974 Gaissau (Austria), Fingstr. 32.

\section{References of notes}

1) Schelling F. Möglichkeiten der endogenen traumatisation von gehirn, rückenmark und nervenwurzeln [On a possible endogenous traumatization of brain, spinal cord, and nerve roots]. Selfpublication Dornbirn (Austria) 1982.

2) Schelling F. Do venous refluxes hurt the brain in MS? The fundamental problem. In: Gonsette R.E., Delmotte P. (eds) Immunological and Clinical Aspects of Multiple Sclerosis. Springer, Dordrecht, 1984. DOI: https://doi.org/10.1007/978-94-011-6352-1_88. pISBN 978-94-011-6354-5. eISBN 978-94-011-6352-1.

3) Schelling F. MR Imaging in multiple sclerosis: an indication of a basic change. Poster to the II European Congress of EMF and European Society of Nuclear Magnetic Resonance (NMR) in Medicine and Biology (ESMRMB), Berlin, Jun 1988. Available at the addresses https://www.dropbox.com/s/c8tb2032zl820jm/ SCHELLING\%201988\%20POSTER\%20FRONT\%20PAGE.pdf?

$\underline{\mathrm{dl}=0}$ and $\mathrm{https}: / / w w w . d r o p b o x . c o m / s / j p q e 0$ epfotcoqtj/Discovery $\% 20$ of $\% 20$ the $\% 20$ Venous $\% 20$ Origin $\% 20$ of $\% 20$ Cerebral $\% 20$ Multiple $\% 20$ Sclerosis $\% 20-\% 20$ Franz $\% 20$ Schelling $\% 201988 \% 20$ copy.pdf?dl=0

4) Adams CWM. A colour atlas of multiple sclerosis. London, Wolfe 1989, pp. 184-95, Fig. 429

5) Schacht L, Minauf M. Zentrale Hirnschäden nach Einwirkung stumpfer Gewalt auf den Schädel [Central brain damages in blunt cranial trauma]. Arch Psychiat Zschr ges Neur 1965;207:416-27 